\title{
An Orally Active Cannabis Extract with High Content in Cannabidiol attenuates Chemically-induced Intestinal Inflammation and Hypermotility in the Mouse
}

\author{
Ester Pagano 1,2, Raffaele Capasso 1,2*, Fabiana Piscitelli2,3, Barbara Romano ${ }^{1,2}$, \\ Olga A. Parisi', Stefania Finizio', Anna Lauritano ${ }^{2,3}$, Vincenzo Di Marzo ${ }^{2,3}$, \\ Angelo A. Izzo ${ }^{1,2}$ and Francesca Borrelli, ${ }^{1 *}$
}

'Department of Pharmacy, University of Naples Federico II, Naples, Italy, ${ }^{2}$ Institute of Bimolecular Chemistry, ICB, National Research Council, Pozzuoli, Italy, ${ }^{3}$ Institute of Biomolecular Chemistry, Consiglio Nazionale delle Ricerche, Pozzuoli, Italy

OPEN ACCESS

Edited by:

Giuseppe Esposito,

Sapienza University of Rome, Italy

Reviewed by:

Mohammad Bashashati, Texas Tech University Health

Sciences Center, USA

Inmaculada Posadas, University of Castilla-La Mancha,

Spain

*Correspondence:

Raffaele Capasso rafcapas@unina.it

Francesca Borrelli franborr@unina.it

Specialty section:

This article was submitted to Gastrointestinal and Hepatic

Pharmacology,

a section of the journal

Frontiers in Pharmacology

Received: 27 July 2016 Accepted: 12 September 2016

Published: 04 October 2016

Citation:

Pagano E, Capasso R, Piscitelli $F$ Romano $B$, Parisi $O A$, Finizio $S$, Lauritano A, Di Marzo V, Izzo AA and

Borrelli F (2016) An Orally Active Cannabis Extract with High Content

in Cannabidiol attenuates

Chemically-induced Intestinal Inflammation and Hypermotility

in the Mouse.

Front. Pharmacol. 7:341 doi: 10.3389/fphar.2016.00341
Anecdotal and scientific evidence suggests that Cannabis use may be beneficial in inflammatory bowel disease (IBD) patients. Here, we have investigated the effect of a standardized Cannabis sativa extract with high content of cannabidiol (CBD), here named CBD BDS for "CBD botanical drug substance," on mucosal inflammation and hypermotility in mouse models of intestinal inflammation. Colitis was induced in mice by intracolonic administration of dinitrobenzenesulfonic acid (DNBS). Motility was evaluated in the experimental model of intestinal hypermotility induced by irritant croton oil. CBD BDS or pure CBD were given - either intraperitoneally or by oral gavage - after the inflammatory insult (curative protocol). The amounts of CBD in the colon, brain, and liver after the oral treatments were measured by high-performance liquid chromatography coupled to ion trap-time of flight mass spectrometry. CBD BDS, both when given intraperitoneally and by oral gavage, decreased the extent of the damage (as revealed by the decrease in the colon weight/length ratio and myeloperoxidase activity) in the DNBS model of colitis. It also reduced intestinal hypermotility (at doses lower than those required to affect transit in healthy mice) in the croton oil model of intestinal hypermotility. Under the same experimental conditions, pure CBD did not ameliorate colitis while it normalized croton oil-induced hypermotility when given intraperitoneally (in a doserelated fashion) or orally (only at one dose). In conclusion, CBD BDS, given after the inflammatory insult, attenuates injury and motility in intestinal models of inflammation. These findings sustain the rationale of combining CBD with other minor Cannabis constituents and support the clinical development of CBD BDS for IBD treatment.

Keywords: Cannabis sativa, cannabidiol, cannabinoids, inflammatory bowel disease, colitis, intestinal motility

\section{INTRODUCTION}

Inflammatory bowel disease (IBD) is a a chronic immunologically mediated disease with growing incidence and prevalence rates in industrialized countries (Ananthakrishnan, 2015; Taleban et al., 2015). Effective pharmacotherapies for IBD are not always available and existing drugs may cause substantial side-effects leading to poor patient adherence. The anecdotal use of marijuana and/or preparations from Cannabis sativa L. (hemp) in IBD patients has been recently confirmed by 
investigations in humans (Ravikoff Allegretti et al., 2013; Naftali et al., 2014; Storr et al., 2014; Izzo et al., 2015). For example, a large-scale population based survey has recently suggested that IBD patients experience symptom relief with marijuana use (Weiss and Friedenberg, 2015). The C. sativa plant produces over 100 terpenophenolic molecules, i.e., the phytocannabinoids, which accumulates predominantly in the plant glandular trichomes (Russo, 2011). Clearly, the most known among the phytocannabinoids is $\Delta^{9}$-tetrahydrocannabinol (THC), whose possible clinical use is hindered by its psychoactivity. This obstacle has addressed further research toward non-psychotropic phytocannabinoids such as cannabidiol (CBD), the versatile pharmacology of which is well established (Esposito et al., 2013; Welty et al., 2014; Brodie et al., 2015; Burstein, 2015; McPartland et al., 2015).

Among numerous pharmacological actions of potential therapeutic interest, pure CBD has been shown to ameliorate experimental colitis (Borrelli et al., 2009; Jamontt et al., 2010; Schicho and Storr, 2012) and to normalize motility in the inflamed mouse gut (Capasso et al., 2008; Lin et al., 2011). It is worthy of note that the beneficial effects of pure CBD in the inflamed gut have been not observed/evaluated after oral gavage (intragastric) administration, a route of drug administration which is easy to be translated to humans for therapeutic use. In the past few years, the contribution of minor phytocannabinoids to the complex Cannabis pharmacology has been shown (Pertwee, 2008; Hill et al., 2012; McPartland and Russo, 2014) and a number of examples of additive/synergistic effects among the phytocannabinoids have been reported (Williamson and Evans, 2000; Wilkinson et al., 2003; DeLong et al., 2010; Jamontt et al., 2010; Russo, 2011; McPartland and Russo, 2014). This observation prompted the cultivation of specific C. sativa chemotypes (chemical genotypes) with high yields of a specific cannabinoid (Potter, 2014). To produce a C. sativa extract, the flowers of female plants are immersed in liquid carbon dioxide at extremely high pressure and the chemical compounds dissolving in this solvent are then separated and purified (Potter, 2014). One of the best studied among such extracts is the standardized C. sativa extract with high content of CBD, generally referred to as CBD BDS (an acronym for Botanical Drug Substance). Notably, CBD BDS is a major ingredient of the medicine known with the generic name nabiximols (Sativex ${ }^{\circledR}$; GW Pharmaceuticals, Cambridge, UK), approved in many countries for the treatment of refractory spasticity in multiple sclerosis (Syed et al., 2014). In the present study, we have examined the effect of CBD BDS in the murine model of colitis induced by dinitrobenzenesulfonic acid. In addition, because motility alterations represent an hallmark in IBD patients, we also investigated the effect of the C. sativa extract in the model of intestinal dysmotility induced by the pro-inflammatory agent croton oil.

\section{MATERIALS AND METHODS}

\section{Drugs and Reagents}

A standardized C. sativa extract with high content in CBD (CBD BDS, $63.9 \% \mathrm{w} / \mathrm{w}$ of CBD content) and pure CBD, [purity by high-performance liquid chromatography (HPLC), 99\%] were supplied by GW Pharmaceuticals (Cambridge, UK). The dose of $\mathrm{CBD}$ BDS used in the experiments refers to the amount of CBD contained in the extract (e.g., $10 \mathrm{mg} / \mathrm{kg}$ of CBD BDS indicates a dose of the BDS that contains $10 \mathrm{mg} / \mathrm{kg}$ of CBD). 2,4,6-dinitrobenzenesulfonic acid (DNBS), croton oil and myeloperoxidase (MPO) from human leucocytes, were purchased from Sigma Aldrich S.r.l. (Milan, Italy). Pure CBD and CBD BDS were dissolved in ethanol/Tween20/saline (1:1:8) for i.p. injection $(60 \mu \mathrm{l} /$ mouse $)$ or in sesame oil $(90 \mu \mathrm{l} /$ mouse) for oral gavage administration. DNBS was solubilized in 50\% ethanol (0.15 ml/mouse). The pure CBD and CBD BDS vehicles had no significant effects on the responses under study.

\section{Plant Material Extraction and Composition of the Cannabis Extract}

A C. sativa chemotype with a controlled high amount of CBD (de Meijer et al., 2003) was used for the preparation of CBD BDS. Details about the extraction, purification as well as typical HPLC chromatogram are reported elsewhere (Romano et al., 2014). The composition (\%,w/w) of the main phytocannabinoids in CBD BDS was CBD $63.9 \pm 5.9, \Delta^{9}$-THC 3.0. cannabigerol 2.8, cannabichromene 3.1, cannabidivarin 1.4. The extract was prepared in GW Pharmaceuticals laboratories (Cambridge, UK).

\section{Animals}

Male ICR mice, weighing 20-25 g for upper gastrointestinal transit experiments and 25-30 g for colitis experiments, were obtained from Charles River Laboratories (Calco, Lecco, Italy) and housed in polycarbonate cages under a $12 \mathrm{~h} \mathrm{light/dark} \mathrm{cycle}$ with light on at 07:00 a.m., controlled temperature $\left(23 \pm 2^{\circ} \mathrm{C}\right)$ and constant humidity $(60 \%)$. Mice were fed ad libitum with standard food, except for the $24 \mathrm{~h}$ period immediately preceding the administration of DNBS, for the $12 \mathrm{~h}$ period preceding the measurement of intestinal transit and for the $2 \mathrm{~h}$ period preceding the oral gavage of drugs. All experiments complied with the Italian D.L. no. 116 of 27 January 1992 and associated guidelines in the European Communities Council Directive of 24 November 1986 (86/609/ECC). According to recent preclinical guidelines in pharmacology, group data subjected to statistical analysis had a minimum of $n=5$ independent animals per group (Curtis et al., 2015).

\section{Induction of Experimental Colitis}

Colitis was induced by the intracolonic administration of DNBS as described before (Borrelli et al., 2015). Briefly, mice were anesthetized with inhaled 5\% isoflurane (Centro Agrovete Campania, Scafati, SA, Italy) and DNBS $(150 \mathrm{mg} / \mathrm{kg})$ was injected in the distal colon using a polyethylene catheter $(1 \mathrm{~mm}$ in diameter) via the rectum ( $4.5 \mathrm{~cm}$ from the anus). All animals were sacrificed 3 days after DNBS administration by asphyxiation with $\mathrm{CO}_{2}$, the mice abdomen was opened by a midline incision and the colon removed, isolated from surrounding tissues, opened along the antimesenteric border, rinsed, weighed, and length measured [in order to determined the colon weight/colon length ratio $(\mathrm{mg} / \mathrm{cm})$, used as an indirect marker of inflammation]. Mice 
body weight was measured every day throughout the treatment period. All measurements were performed by operators who were unaware of the particular treatment (blinded evaluation). For biochemistry analysis, tissues were kept at $80^{\circ} \mathrm{C}$ until use. The dose of DNBS $(150 \mathrm{mg} / \mathrm{kg})$ and the time point of damage evaluation (i.e., 3 days after DNBS administration) were selected on the basis of preliminary experiments showing a remarkable colonic damage associated with high reproducibility and low mortality for this dosage, and because maximal DNBS-induced inflammation has been reported in mice after 3 days (Massa et al., 2004).

\section{Intestinal Hypermotility Induced by Croton Oil}

Increased intestinal motility was induced by the inflammatory agent croton oil as described before ( $\mathrm{Pol}$ and Puig, 1997; Capasso et al., 2008). Briefly, two doses of croton oil (20 $\mu \mathrm{l} /$ mouse) for two consecutive days were orally administered to mice and 4 days after the first administration of croton oil, upper gastrointestinal transit of mice was measured. This time was selected on the basis of previous work ( $\mathrm{Pol}$ and Puig, 1997), which reported that the maximal inflammatory response associated to intestinal hypermotility occurs 4 days after the first treatment.

\section{Upper Gastrointestinal Transit}

Upper gastrointestinal transit, measured in control, and in mice with intestinal inflammation-induced accelerated intestinal motility (mice treated with croton oil), was evaluated by identifying the leading front of an intragastrically administered charcoal meal marker $(10 \%$ charcoal suspension in $5 \%$ gum Arabic, $10 \mathrm{ml} / \mathrm{kg}$ ) in the small intestine as previously described (Capasso et al., 2014). Twenty minutes after charcoal administration, mice were killed by asphyxiation with $\mathrm{CO}_{2}$, and the small intestine was isolated by cutting at the pyloric and ileocaecal junctions. The distance traveled by the marker was measured and expressed as a percentage of the total length of the small intestine from pylorus to caecum.

\section{Pharmacological Treatment}

In the experimental model of colitis pure CBD, CBD BDS or vehicle were given intraperitoneally $(5-30 \mathrm{mg} / \mathrm{kg}$ ) or by oral gavage (10-60 mg/kg) for three consecutive days starting $24 \mathrm{~h}$ after DNBS administration [Day 0: colitis induction; day 1: CBD $\mathrm{BDS}$ (or $\mathrm{CBD}$ ); day 2: $\mathrm{CBD} \mathrm{BDS}$ (or $\mathrm{CBD}$ ); day 3: $\mathrm{CBD} \mathrm{BDS}$ (or $\mathrm{CBD)}$ and mice sacrifice]. The last administration of $\mathrm{CBD}$ $\mathrm{BDS}$ (or CBD) was given (at day 3) $1 \mathrm{~h}$ (for intraperitoneal administration) or $2 \mathrm{~h}$ (for oral gavage) before the sacrifice.

In the experimental model of upper gastrointestinal transit pure $\mathrm{CBD}, \mathrm{CBD} \mathrm{BDS}$, or vehicle were given intraperitoneally $(1-10 \mathrm{mg} / \mathrm{kg})$ or by oral gavage $(5-60 \mathrm{mg} / \mathrm{kg}) \quad 30 \mathrm{~min}$ (intraperitoneally) or $1 \mathrm{~h}$ (oral gavage) before the administration of the marker, to both control mice, and mice with increased intestinal motility induced by the inflammatory agent croton oil. The CBD BDS and pure CBD doses were selected on the basis of previously published work (Borrelli et al., 2009; Romano et al., 2014).

\section{Myeloperoxidase (MPO) Activity}

Myeloperoxidase activity, a peroxidase enzyme used to quantify the neutrophil infiltration in whole-tissue colons, was determined as previously described (Borrelli et al., 2015). Full-thickness colons were homogenized in a lysis buffer composed of $0.5 \%$ hexadecyltrimethylammonium bromide in 3-( $\mathrm{N}$ morpholino) propanesulfonic acid (MOPS) $10 \mathrm{mM}$ in the ratio of $50 \mathrm{mg}$ tissue per $\mathrm{mL}$ MOPS. The homogenates were then centrifuged for $20 \mathrm{~min}$ at $15,000 \times g$ at $4^{\circ} \mathrm{C}$. An aliquot of the supernatant was incubated with sodium phosphate buffer (NaPP pH 5.5) and tetra-methylbenzidine $16 \mathrm{mM}$. After $5 \mathrm{~min}$, hydrogen peroxide $\left(\mathrm{H}_{2} \mathrm{O}_{2} ; 9.8 \mathrm{M}\right.$ in $\left.\mathrm{NaPP}\right)$ was added and the reaction stopped with acetic acid. The rate of change in absorbance was measured by a spectrophotometer at $650 \mathrm{~nm}$. Different dilutions of human MPO enzyme of known concentration were used to obtain a standard curve. MPO activity was expressed as $\mathrm{U} / \mathrm{mg}$ of tissue.

\section{Tissue CBD Assay: Extraction, Purification, and LC IT-TOF Mass Spectrometry}

Colon, liver, and brain samples were dounce-homogenized and extracted with acetone containing internal deuterated standards for CBD quantification by isotope dilution $\left(\left[{ }^{2} \mathrm{H}\right]_{4} \mathrm{CBD}\right)$. The lipid-containing organic phase was dried down, weighed, and pre-purified by open bed chromatography on silica gel. Fractions were obtained by eluting the column with 99:1, 90:10, and 50:50 (v/v) chloroform/methanol. The 99:1 fraction was used for CBD quantification by LC-MS-IT-TOF analysis using an LC20AB coupled to a hybrid IT-TOF detector (Shimadzu Corporation, Kyoto, Japan) equipped with an ESI interface. We acquired fullscan $\mathrm{MS}^{\mathrm{n}}$ spectra of selected precursor ions by multiple reaction monitoring (MRM), extracted the chromatograms of the highresolution $[\mathrm{M}-\mathrm{H}]^{-}$values and used the latter chromatograms for calibration and quantification.

\section{HPLC Parameters}

Liquid chromatography analysis was performed in the isocratic mode using a KinetexC18 column $(10 \mathrm{~cm} \times 2.1 \mathrm{~mm}$, I.D. $5 \mu \mathrm{m}$, $100 \mathrm{~A}$; Phenomenex) and methanol:water (75:25) with $0.1 \%$ $\mathrm{NH}_{4} \mathrm{C}_{2} \mathrm{H}_{3} \mathrm{O}_{2}$ as mobile phase with a flow rate of $150 \mu \mathrm{l} / \mathrm{min}$. The samples were injected with a SIL-20 AC autosampler (Shimadzu Corporation, Kyoto, Japan). The amounts of CBD in tissues, quantified by isotope dilution with the abovementioned deuterated standard, are expressed as ng per mg of tissue weight.

\section{Mass Spectrometry Parameters}

Electrosprayed ions were generated using a capillary voltage of $4.66 \mathrm{kV}$. A curved desolvation line (CDL) was set at a temperature of $250^{\circ} \mathrm{C}$ to aid desolvation and a heat block temperature of $220^{\circ} \mathrm{C}$ was also used. To help nebulisation of the electrospray solution nitrogen was pumped into the ion source at a rate of $1.5 \mathrm{~L} / \mathrm{min}$. The ToF mass analyzer was used to acquire data in both MS and MS/MS modes. In the MS mode, a $10 \mathrm{~ms}$ ion accumulation time was used before ion trapping. In the MSMS mode, instead, the ion accumulation time was $20 \mathrm{~ms}$ and the window used for precursor ion isolation corresponds to 
a width of 3 atomic mass unit (amu) and $20 \mathrm{~ms}$. To induce fragmentation of the precursor ion a supplementary alternative current (AC) potential was applied to the end-cap electrodes to induce resonant excitation and argon is used as a collision gas during collision-induced dissociation (CID). The collision was carried out over $30 \mathrm{~ms}$ using a $q$-value of $0.251(45 \mathrm{kHz})$. Three scans were accumulated in each MS-MS spectrum. In both MS and MS-MS mode data were acquired over a mass range of 200$500 \mathrm{~m} / z$. In both regimes of operation ions are pulsed into the time of flight (ToF) with an accelerating potential of $9 \mathrm{kV}$ and the detector voltage is set at $1.7 \mathrm{kV}$ (Piscitelli et al., 2011).

Full details of the quantification of CBD using LC-MS-IT-ToFMS will be published elsewhere (Piscitelli et al., 2011, manuscript in preparation].

\section{Statistical Analysis}

Data are expressed as the mean \pm SEM of $n$ experiments. To determine statistical significance, Student's $t$-test was used for comparing a single treatment mean with a control mean, and a one-way ANOVA followed by a Tukey-Kramer multiple comparisons test was used for analysis of multiple treatment means. $P$-values $<0.05$ were considered significant.

\section{RESULTS}

\section{Effect of CBD BDS and Pure CBD on Body Weight and Colon Weight/Colon Length Ratio}

The administration of DNBS caused both a significant decrease in body weight and a significant increase in colon weight/length ratio when compared to control mice (Figures $\mathbf{1}$ and 2 ). Treatment of DNBS mice with CBD BDS, given intraperitoneally at the range dose of $5-30 \mathrm{mg} / \mathrm{kg}$, did not modify the loss of body weight induced by the inflammatory agent (Figure 1A) but reduced DNBS-increased colon weight/length ratio (Figure 1B). The effect was significant at the $30 \mathrm{mg} / \mathrm{kg}$ dose (Figure 1B). Likewise, oral gavage administration of CBD BDS (10-60 mg/kg)
A

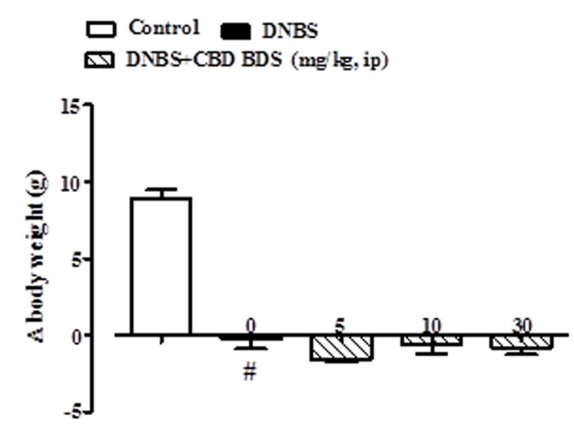

C

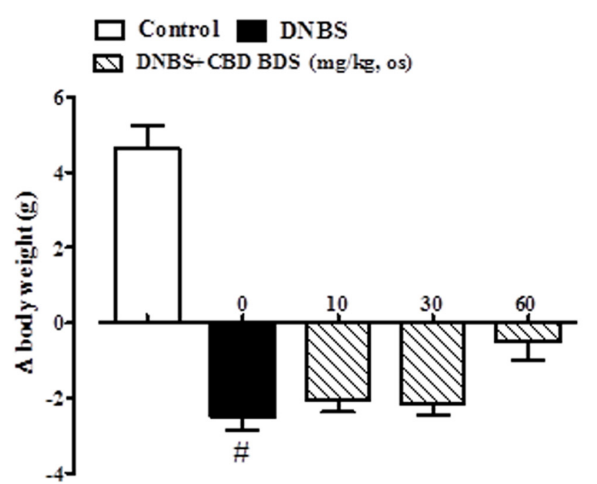

B

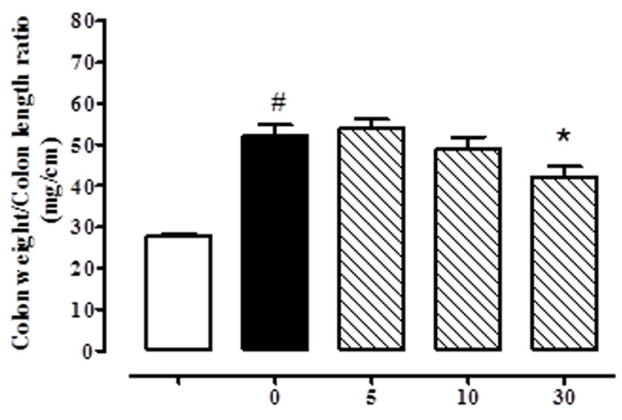

D

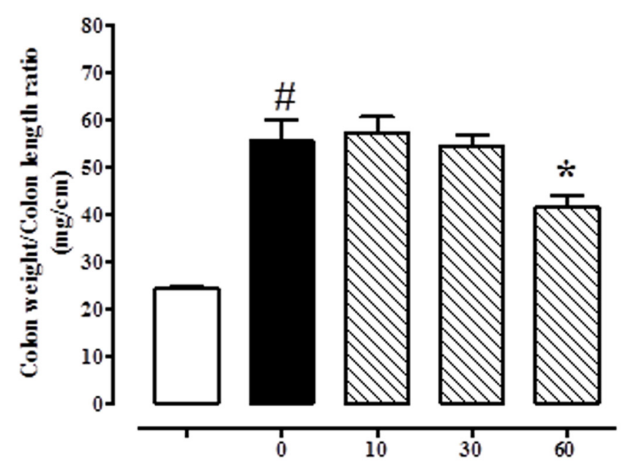

FIGURE 1 | Effect of CBD BDS (5-30 mg/kg, intraperitoneally) on body weight (A) and colon weight/colon length ratio (B) and effect of CBD BDS (10-60 mg/kg, oral gavage) on body weight (C) and colon weight/colon length ratio (D) in DNBS induced colitis in mice (DNBS, $150 \mathrm{mg} / \mathrm{kg}$, intracolonically). CBD BDS was given once a day for three consecutive days starting from 1 day after DNBS administration. Mice were euthanized 3 days after DNBS. Mice were weighted before DNBS (or vehicle) administration and immediately before the sacrifice. Bars are mean \pm SEM of 8-12 mice for each experimental group. ${ }^{*} p<0.001$ vs. control and ${ }^{*} p<0.05$ vs. DNBS alone. 
A

Control DNBS

$\triangle$ DNBS-CBD (mg/kg, ip)

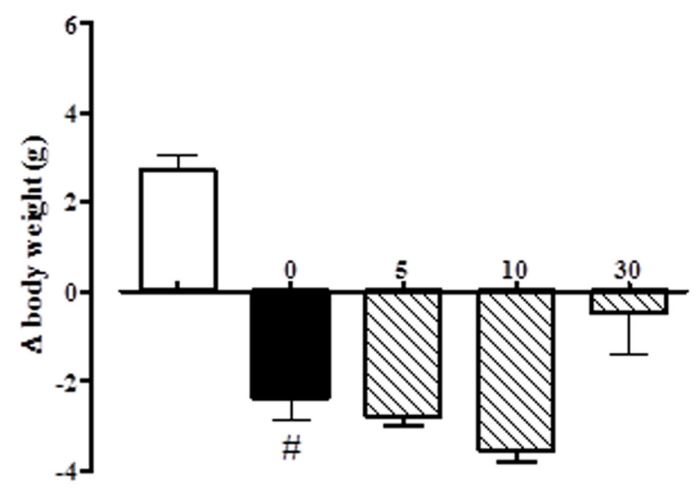

C

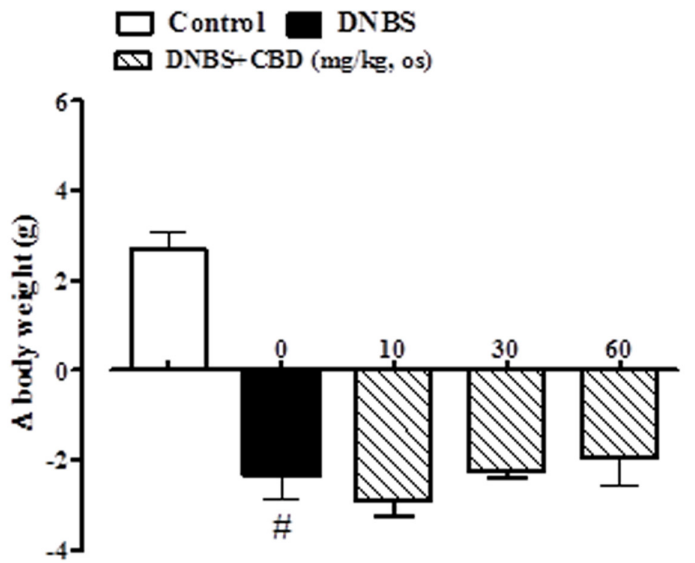

B

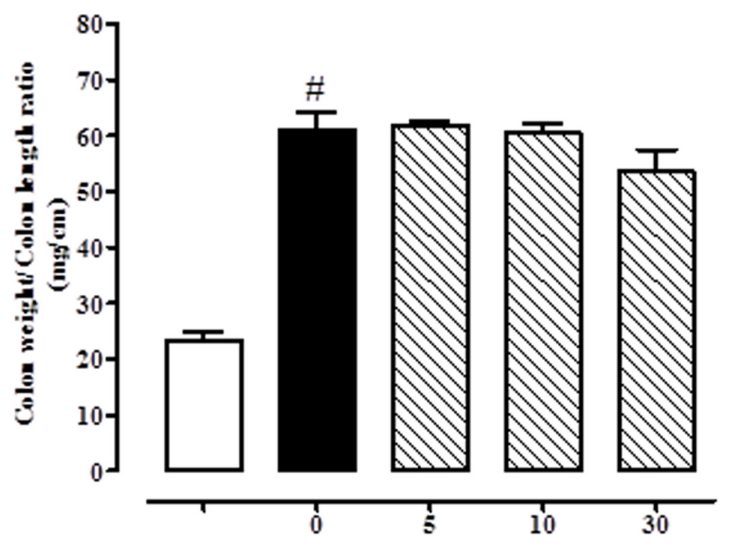

D

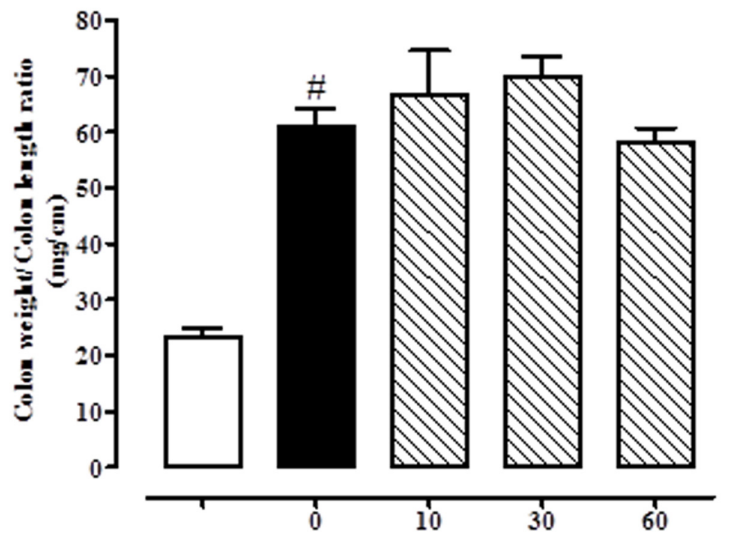

FIGURE 2 | Effect of pure CBD (5-30 mg/kg, intraperitoneally) on body weight (A) and colon weight/colon length ratio (B) and effect of pure CBD (10-60 mg/kg, by oral gavage) on body weight (C) and colon weight/colon length ratio (D) in DNBS induced colitis in mice (DNBS, $150 \mathrm{mg} / \mathrm{kg}$, intracolonically). Pure CBD was given once a day for three consecutive days starting from 1 day after DNBS administration. Mice were euthanized 3 days after DNBS. Mice were weighted before DNBS (or vehicle) administration and immediately before the sacrifice. Bars are mean \pm SEM of 8-12 mice for each experimental group. ${ }^{\#} p<0.001$ vs. control.

had no effect on the DNBS-induced decrease in body weight, although a trend in reducing weight loss was observed at the $60 \mathrm{mg} / \mathrm{kg}$ dose (Figure 1C). CBD BDS, given via oral gavage at the $60 \mathrm{mg} / \mathrm{kg}$ dose, significantly reduced the colon weight/length ratio increased by DNBS (Figure 1D).

Pure CBD, when both given intraperitoneally $(5-30 \mathrm{mg} / \mathrm{kg})$ or by oral gavage $(10-60 \mathrm{mg} / \mathrm{kg})$, did not ameliorate DNBS-induced colitis (no variation on body weight and colon weight/colon length ratio; Figure 2).

\section{Effect of CBD BDS on MPO Activity}

The beneficial effect of CBD BDS on DNBS-induced colitis was further confirmed by the MPO results. DNBS administration produced a threefold increase in MPO activity which was significantly reduced by either intraperitoneal or oral gavage administration of CBD BDS at the $30 \mathrm{mg} / \mathrm{kg}$ and $60 \mathrm{mg} / \mathrm{kg}$ dose, respectively (Figure 3).

\section{Effect of Pure CBD and CBD BDS on Upper Gastrointestinal Transit}

CBD BDS, given intraperitoneally at the dosage range of $1-10 \mathrm{mg} / \mathrm{kg}$, reduced the intestinal transit in healthy mice, the effect being significant only at the higher dose tested (10 mg/kg; Figure 4A). CBD BDS (1-10 mg/kg), in a dose dependent manner, counteracted the increase in intestinal motility induced by croton oil (Figure 4B). The effect was significant starting from the $1 \mathrm{mg} / \mathrm{kg}$ dose. Analysis of the curves representing the inhibitory effect of CBD BDS on transit 


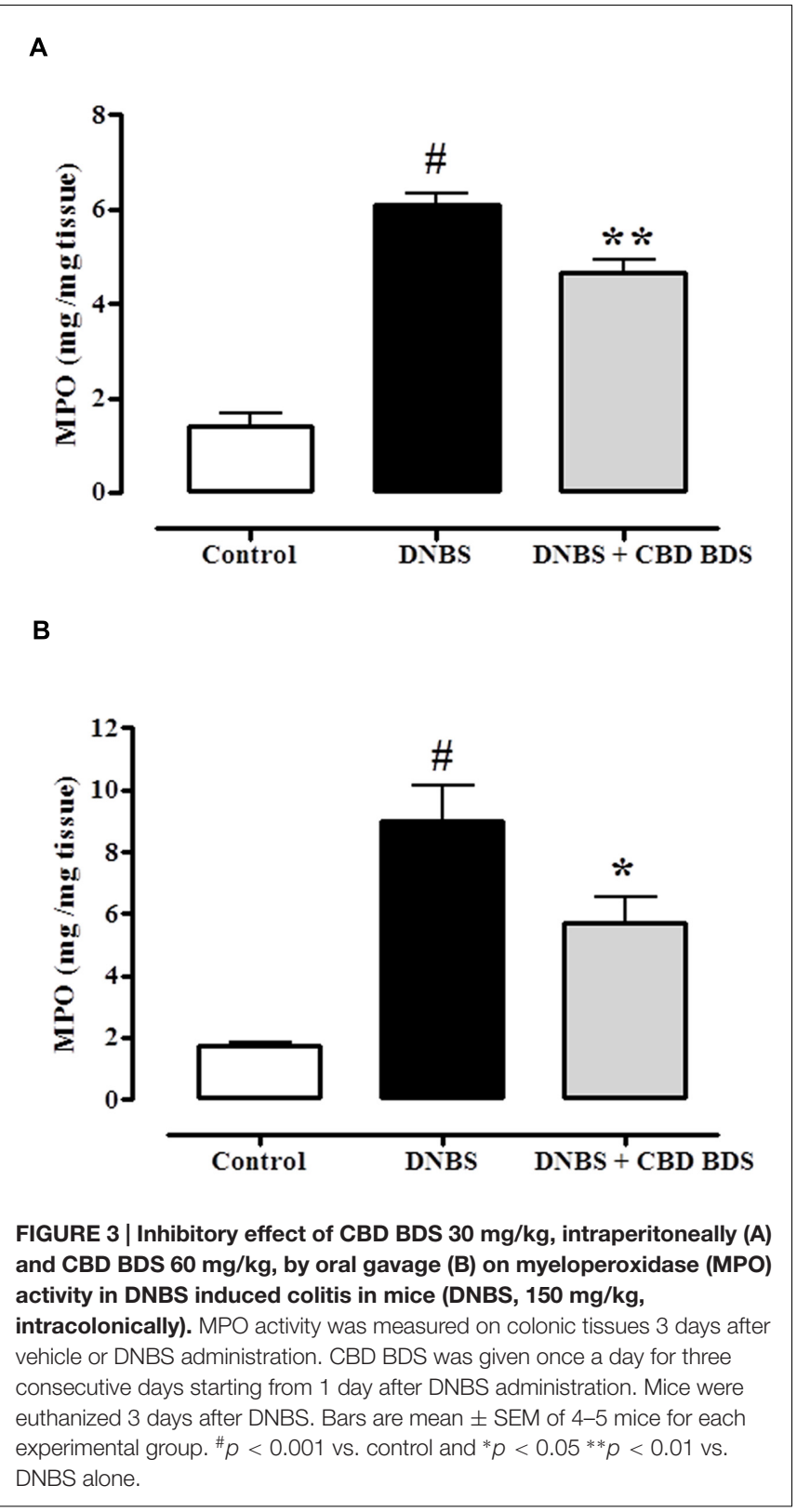

in healthy mice and in mice with hypermotility induced by croton oil shows that CBD BDS preferentially inhibited intestinal transit in pathophysiological rather than physiological conditions (Figure 4). Likewise, CBD BDS when given by oral gavage at the dosage range of $5-60 \mathrm{mg} / \mathrm{kg}$ reduced the intestinal transit in healthy mice, the effect being significant starting from the $10 \mathrm{mg} / \mathrm{kg}$ dose (Figure 5A). Similar to the intraperitoneal administration, oral gavage administration of CBD BDS (5$60 \mathrm{mg} / \mathrm{kg}$ ), in a dose dependent manner, reduced the intestinal hypermotility induced by croton oil (Figure 5B). The effect was significant starting from the $5 \mathrm{mg} / \mathrm{kg}$ dose. Analysis of the curves representing the inhibitory effect of CBD BDS on transit in healthy mice and in mice with hypermotility induced by croton oil shows that CBD BDS, also when given by oral gavage, preferentially inhibited intestinal transit in pathophysiological rather than physiological conditions (Figure 5).

As previously reported (Capasso et al., 2008), pure CBD, given intraperitoneally at the dose range of $1-10 \mathrm{mg} / \mathrm{kg}$, did not affect the intestinal transit in healthy mice (Figure 6A) but, significantly and in a dose dependent manner, restored the intestinal motility in mice with hypermotility induced by croton oil (Figure 6B). The effect was significant starting from the $5 \mathrm{mg} / \mathrm{kg}$ dose (Figure 6B). Oral gavage administration of pure CBD did not reduce intestinal transit in healthy mice (Figure 6C), and reduced the croton oil-induced accelerated intestinal motility at the $5 \mathrm{mg} / \mathrm{kg}$ dose only (Figure 6D).

\section{CBD Levels in Tissues of Mice with DNBS-Induced Inflammation after Oral Treatment with Pure CBD or CBD BDS}

As shown in Figure 7, CBD was detected in the colon, liver, and brain in mice treated with either $\mathrm{CBD}$ BDS or pure $\mathrm{CBD}$ (oral administration). In the colon (Figure 7A) and in the brain (Figure 7B), the content increased with the dose in the case of pure $\mathrm{CBD}$, while in the CBD BDS group there were no differences between the two doses.

In the liver, $\mathrm{CBD}$ tissue penetration was higher with the oral administration of CBD-BDS, in a dose-dependent manner (Figure 7C), while there were no significant differences between pure $\mathrm{CBD}$ at 30 and $60 \mathrm{mg}$. Interestingly, higher $\mathrm{CBD}$ levels were achieved with pure CBD in the colon and brain, and much higher $\mathrm{CBD}$ levels were achieved with CBD BDS in the liver.

\section{DISCUSSION}

The notion that not all of the therapeutic effects of $C$. sativa are due to its many active psychotropic ingredient $\mathrm{THC}$ is well established (Wilkinson et al., 2003; Russo, 2011; Brodie et al., 2015). The contribution of non-THC phytocannabinoids to Cannabis pharmacology has been scientifically demonstrated in a number of experimental diseases, including ulcerative colitis (Duncan and Izzo, 2015). In previous studies, it has been shown that isolated Cannabis constituents, including cannabichromene $(\mathrm{CBC}), \mathrm{CBD}$ and cannabigerol (CBG), exert favorable effects in experimental models of IBD (Borrelli et al., 2009, 2013; Jamontt et al., 2010; Romano et al., 2013). In the present study, we have expanded our knowledge on the intestinal anti-inflammatory effect of phytocannabinoids by showing for the first time that a Cannabis extract with high content in $\mathrm{CBD}$, namely $\mathrm{CBD}$ BDS, when both given intraperitoneally and by oral gavage, is able to reduce the extent of the damage and to counteract intestinal hypermotility in experimental models of intestinal inflammation. By contrast, we demonstrated that pure CBD, either given intraperitoneally or by oral gavage at matched CBD doses with CBD BDS, after the inflammatory insult does not offer anti-inflammatory effects.

The route of administration for cannabinoids is a major issue since cannabinoids are significantly metabolized by hepatic cytochrome enzymes (Huestis, 2005). There is no evidence 
A
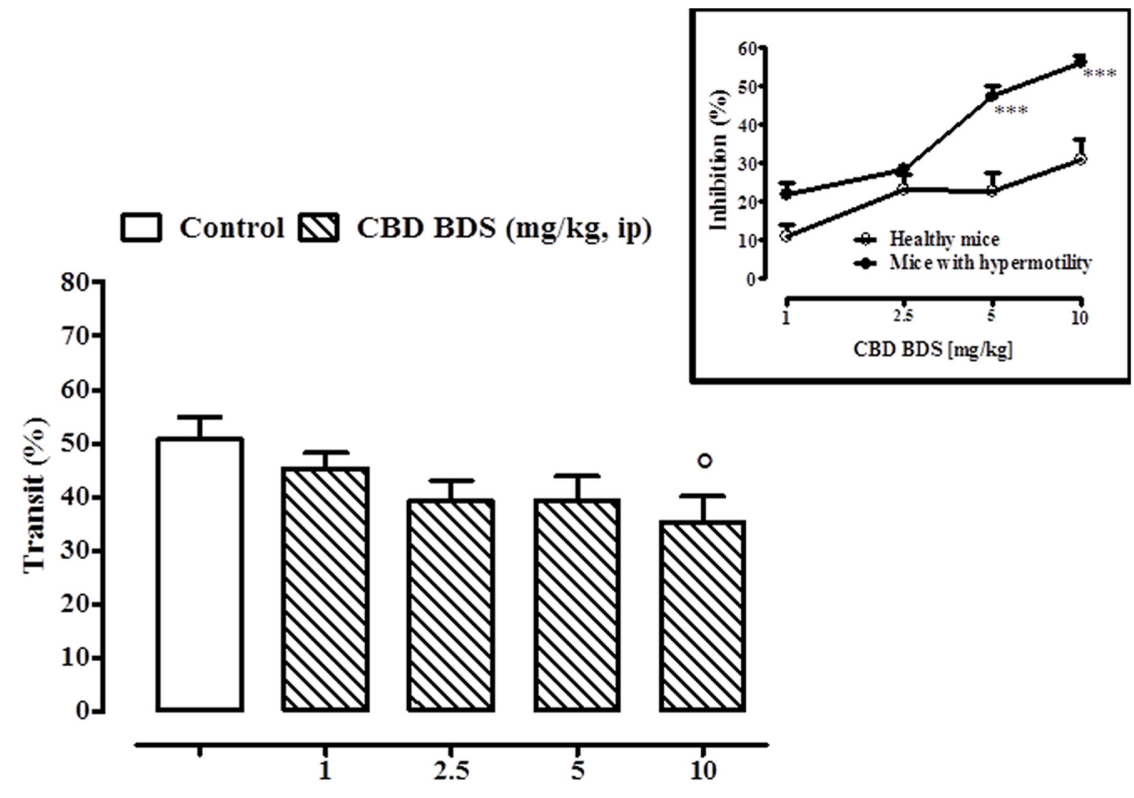

B

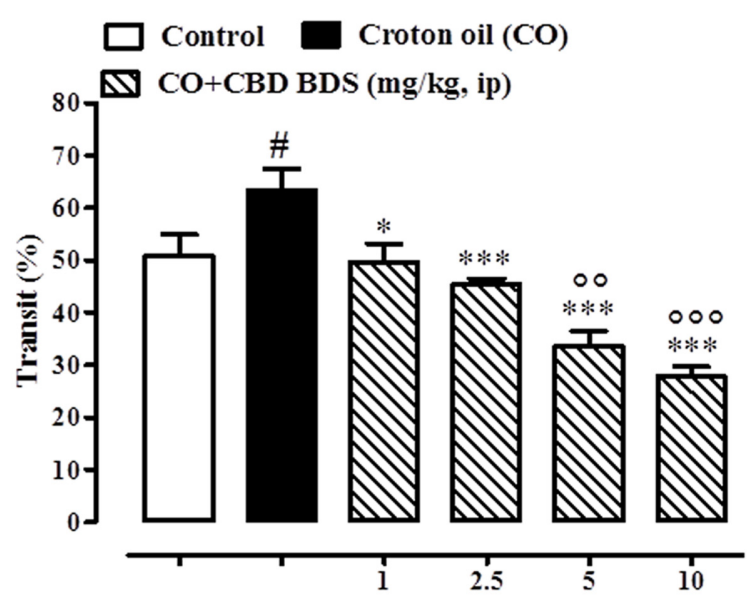

FIGURE 4 | Effect of CBD BDS (1-10 $\mathbf{~ g g / k g}$, intraperitoneally) on intestinal transit in healthy mice (A) and croton oil-treated mice (B). Bars represent the mean \pm SEM of $8-10$ animals for each experimental group. ${ }^{\circ}$ and ${ }^{\#} p<0.05,{ }^{\circ} p<0.01$, and ${ }^{\circ 00} p<0.001$ vs. control and ${ }^{*} p<0.05$ and ${ }^{* * *} p<0.001$ vs. croton oil alone. Insert: Difference between the curves representing the inhibitory effect of CBD BDS on intestinal transit in healthy mice and mice with hypermotility (mice treated with croton oil). Results are expressed as mean \pm SEM of 8-10 mice for each experimental group. ${ }^{* * *} p<0.001$ vs. healthy mice.

in the literature that cannabinoids may exert intestinal antiinflammatory effects when given orally. While the intraperitoneal route of administration is extensively used in rodent experiments, it appears clear that such a way of delivery is hard to be translated to humans. In the present study, we have shown that $\mathrm{CBD}$ BDS, given intraperitoneally or by oral gavage, reduces inflammation associated to DNBS administration. Although we did not provide a microscopic score, as done for CBD in our previous work (Borrelli et al., 2009), the anti-inflammatory effect of CBD BDS was supported by colon length/weight ratio and by the MPO measurements, two well-established marker of intestinal inflammation (Krawisz et al., 1984; Kristjánsson et al., 2004). In addition, CBD BDS (intraperitoneally or orally) was pharmacologically active when administered after the inflammatory insult, which is clinically relevant in the light of the observation that the main goal of IBD pharmacotherapy is to cure rather than to prevent. In previous studies aimed at investigating the intestinal anti-inflammatory effects of Cannabis and its active ingredients, phytocannabinoids, including $\mathrm{CBD}$, were given before the inflammatory insult (i.e., preventive protocol) (Borrelli et al., 2009; Jamontt et al., 2010; Schicho and Storr, 2012). In contrast to CBD BDS, pure CBD does not exert 

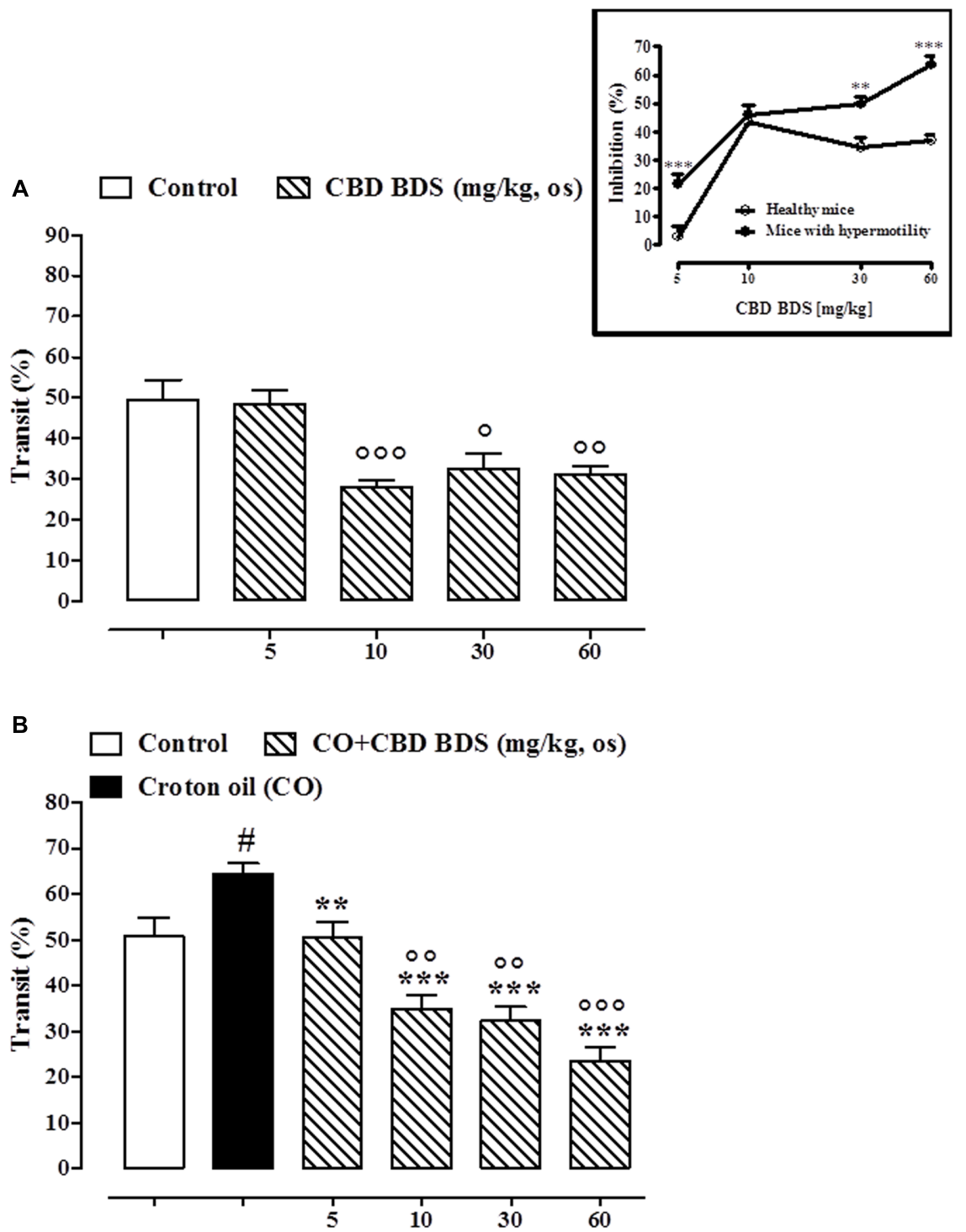

FIGURE 5 | Effect of CBD BDS (10-60 mg/kg, by oral gavage) on intestinal transit in healthy mice (A) and croton oil-treated mice (B). Bars represent the mean \pm SEM of $8-10$ animals for each experimental group. ${ }^{\circ}$ and ${ }^{*} p<0.05,{ }^{\circ} p<0.01$ and ${ }^{\circ 00} p<0.001$ vs. control and ${ }^{* *} p<0.01$ and ${ }^{* * *} p<0.001$ vs. croton oil alone. Insert: Difference between the curves representing the inhibitory effect of CBD BDS on intestinal transit in healthy mice and mice with hypermotility (mice treated with croton oil). Results are expressed as mean \pm SEM of 8-10 mice for each experimental group. ${ }^{* * *} p<0.001$ vs. healthy mice.

anti-inflammatory effects either when given intraperitoneally or by oral gavage even with the high doses. The lack of effect of pure CBD (up to $20 \mathrm{mg} / \mathrm{kg}$ ) after oral gavage, but not after intracolonic, administration has been previous documented (Schicho and Storr, 2012) and may be not surprising if we consider that this type of administration is subjected to a significant first-pass effect (Huestis, 2005).

The difference in efficacy between pure $\mathrm{CBD}$ and $\mathrm{CBD}$ BDS is likely due to the presence of pharmacologically active ingredients. Indeed, in addition to $\mathrm{CBD}, \mathrm{CBD}$ BDS contains other phytocannabinoids, such as THC, CBC, and CBG, which have been previously shown to exert anti-inflammatory effects in experimental models of colitis (Jamontt et al., 2010; Borrelli et al.,
2013; Romano et al., 2013) and whose colonic levels were not determined in the present study. Furthermore non-cannabinoid C. sativa constituents, such as flavonoids, phytosterols, and terpenoids, have been shown to ameliorate murine colitis (Reddy, 1976; Somani et al., 2015; Vezza et al., 2016). On the other hand, the higher efficacy of oral CBD BDS does not seem to be ascribable to higher penetration of $\mathrm{CBD}$ in the colon when using this drug. In fact, we show here that the exposure to CBD of both the colon and brain after oral administration of either pure CBD or $\mathrm{CBD} \mathrm{BDS}$ is higher with the highest dose of pure $\mathrm{CBD}$ than with the highest dose of CBD BDS, and similar with the lowest doses of the two drugs. Conversely, in the liver, the concentration of CBD, at both doses tested, was higher with CBD BDS than with 
A

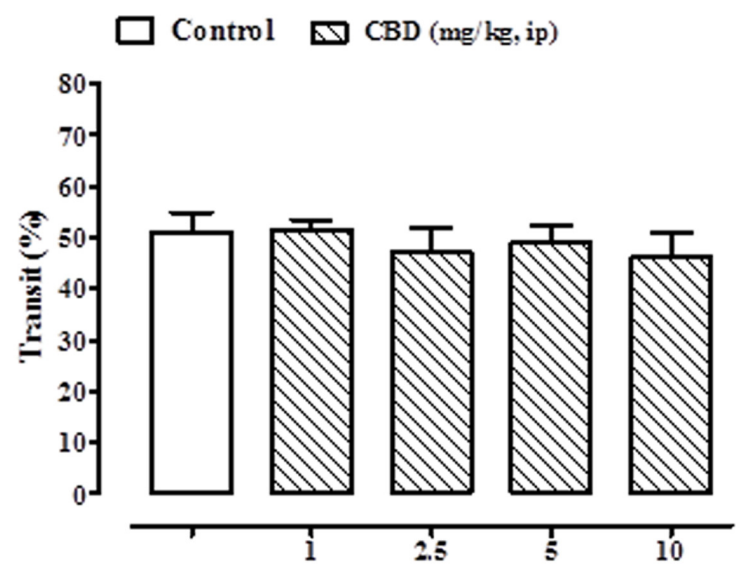

C

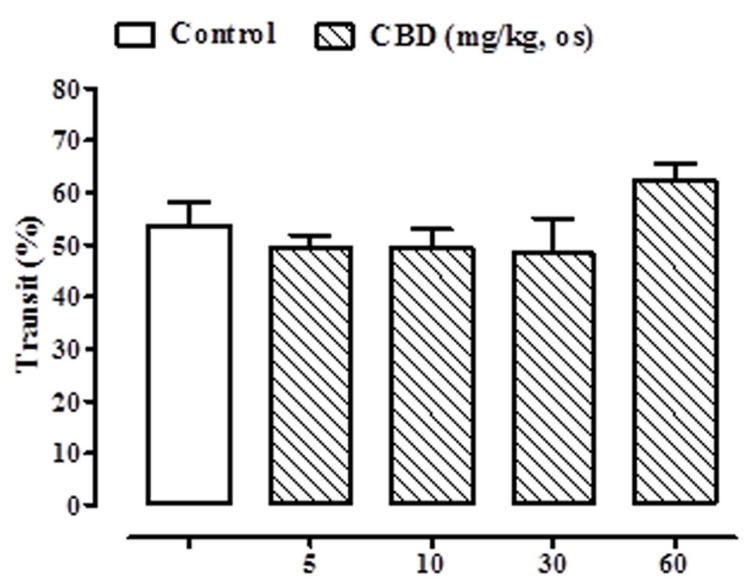

B

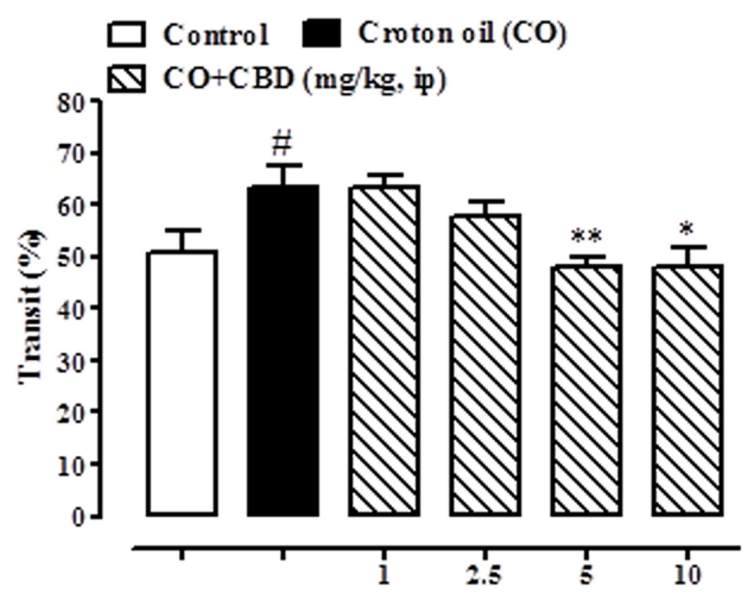

D

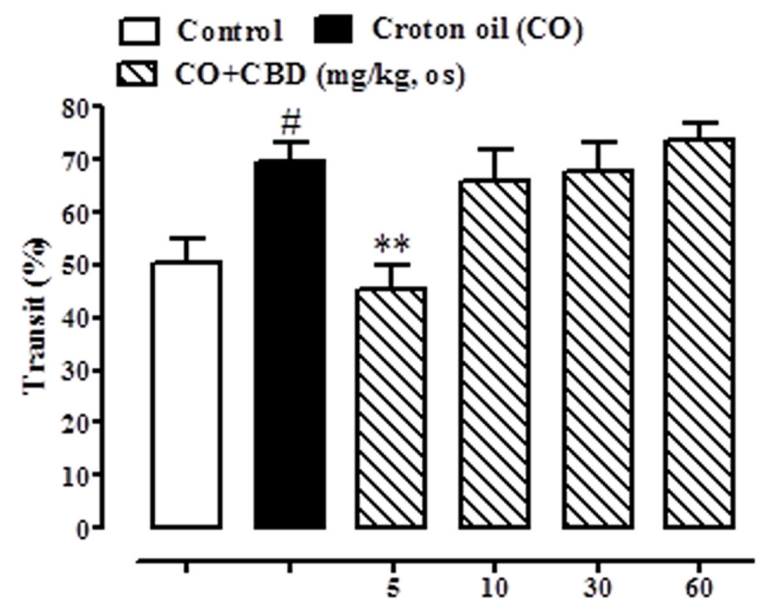

FIGURE 6 | Effect of intraperitoneal administration of pure CBD (1-10 $\mathrm{mg} / \mathrm{kg}$ ) on intestinal transit in healthy mice (A) and croton oil-treated mice (B), and oral gavage administration of pure CBD (5-60 $\mathbf{~ m g} / \mathbf{k g})$ on intestinal transit in healthy mice (C) and croton oil-treated mice (D). Bars represent the mean \pm SEM of 8-10 animals for each experimental group. ${ }^{*} p<0.05-0.01$ vs. control; * $p<0.05$ and ${ }^{* *} p<0.01$ vs. croton oil alone.

pure CBD. Interestingly, the maximal colonic concentrations of $\mathrm{CBD}$ at the end of treatment can be calculated to be $\sim 30 \mathrm{nM}$ with $\mathrm{CBD}$ BDS and $\sim 100 \mathrm{nM}$ with pure $\mathrm{CBD}$, which are not too distant from the potencies of this compound at many of its proposed molecular targets (McPartland and Russo, 2014; Brodie et al., 2015). Others have shown that a non-chemically characterized Cannabis extract reduced the severity of rat colitis when administered intracolonically (Wallace et al., 2013).

Inflammatory states in the gut may cause motility disturbances, and alterations in intestinal motility are common debilitating symptoms (Brierley and Linden, 2014). To investigate the effect of CBD BDS on intestinal motility, we adopted the croton oil model of intestinal inflammation-induced hypermotility. This model has been extensively used in the past to evaluate the potential of drugs able to reduce intestinal motility such as opioids (Pol and Puig, 2004) and cannabinoids (Aviello et al., 2008). By using this experimental model, it has been shown that a number of phytocannabinoids, including $\mathrm{CBD}, \mathrm{CBC}$, and CBN (Izzo et al., 2000, 2012; Capasso et al., 2008), normalize motility during the inflammatory process, with weak or no effect in control mice. In the present study, we have shown that both CBD BDS and pure CBD, given intraperitoneally or by oral gavage, reduce motility in mice with intestinal inflammation, with weak (CBD BDS) or no (pure CBD) effects in control mice. From a translational viewpoint, the low doses of CBD BDS (and pure $\mathrm{CBD}$ ) required to normalize motility in the inflamed gut - as well as their pharmacological activity following oral gavage administration - are relevant if we consider that the drugs available to reduce motility may be often associated with constipation (Corsetti and Tack, 2015; Rao et al., 2016).

The anti-inflammatory mode of action of CBD BDS in the gut is still elusive and deserves further ad hoc studies. CBD 


\section{(COLON)}

A

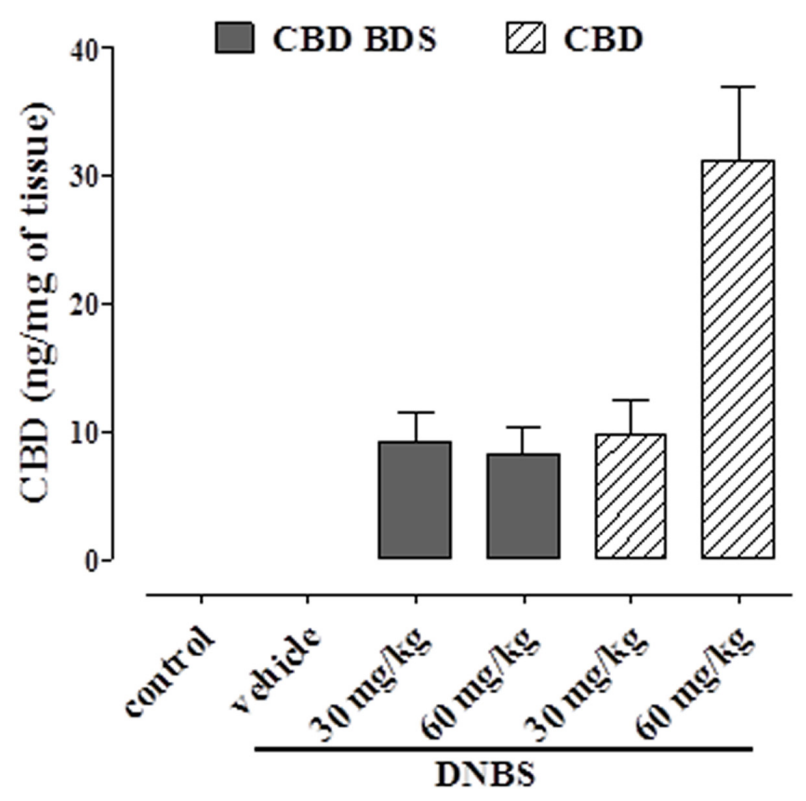

\section{(BRAIN)}

B

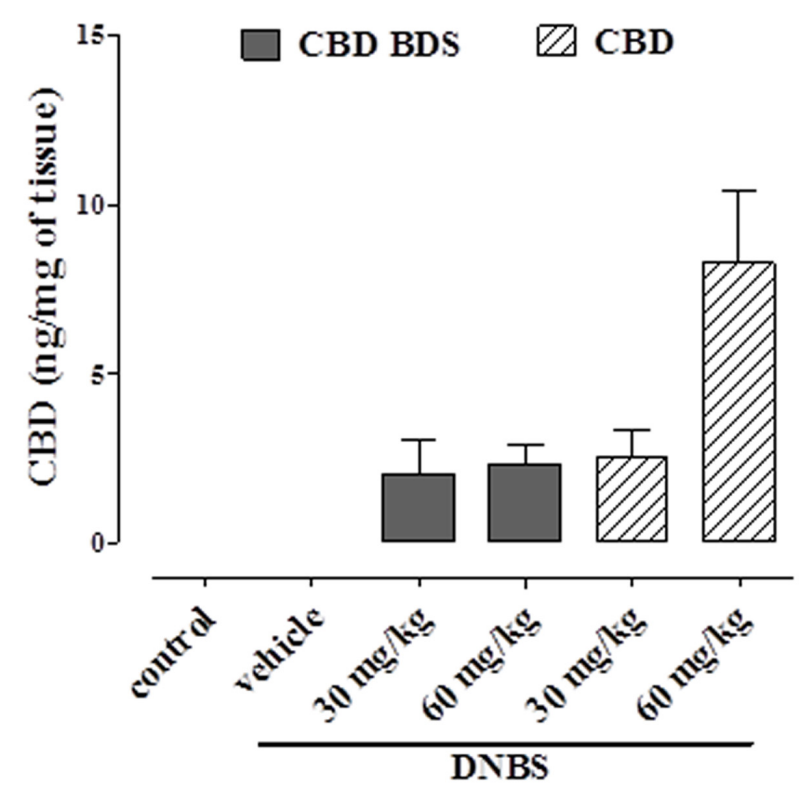

\section{(LIVER)}

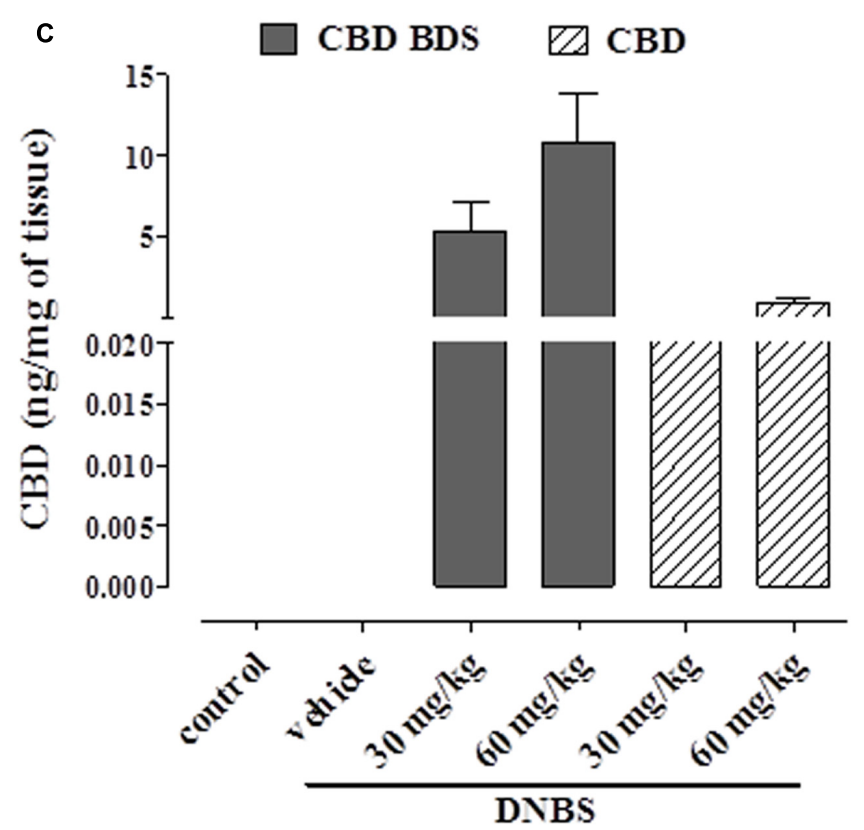

FIGURE 7 | CBD levels in colon (A), brain (B), and liver (C) of DNBS-treated mice after oral administration of either CBD BDS or CBD. Data are means \pm SEM of $N=5-6$ mice.

and other minor phytocannabinoids contained in CBD BDS may interact with targets (e.g., components of the so-called endogenous cannabinoid system, TRP channels; De Petrocellis et al., 2011, 2012) which have been linked to IBD (Izzo et al., 2015; Zielińska et al., 2015). Recently, pharmacological blockade of GPR55 has been shown to protect against experimental gut 
inflammation (Stančić et al., 2015), a relevant finding in the light of the observation that CBD is a GPR55 antagonist (Ryberg et al., 2007; Campos et al., 2012). Conversely, the antioxidant effect is believed to not entirely explain per se the gut anti-inflammatory actions exerted by CBD (Esposito et al., 2013).

\section{CONCLUSION}

The present study reveals for the first time the ability of the CBD BDS to attenuate the severity of inflammation in the DNBS model of colitis, as well as to reduce transit in a model of inflammation-induced dysmotility. The strengths of CBD BDS for a possible clinical use in IBD patients include: (a) its intestinal anti-inflammatory activity following oral gavage administration (in contrast to pure CBD, which was ineffective); (b) its ability to reduce the degree of inflammation in a curative protocol, (c) its ability to reduce motility in the inflamed gut at doses lower than those required to affect motility in control animals. Our results further support the therapeutic rationale for combining

\section{REFERENCES}

Ananthakrishnan, A. N. (2015). Epidemiology and risk factors for IBD. Nat. Rev. Gastroenterol. Hepatol. 12, 205-217. doi: 10.1038/nrgastro.2015.34

Aviello, G., Romano, B., and Izzo, A. A. (2008). Cannabinoids and gastrointestinal motility: animal and human studies. Eur. Rev. Med. Pharmacol. Sci. 12(Suppl. 1), 81-89.

Borrelli, F., Aviello, G., Romano, B., Orlando, P., Capasso, R., Maiello, F., et al. (2009). Cannabidiol, a safe and non-psychotropic ingredient of the marijuana plant Cannabis sativa, is protective in a murine model of colitis. J. Mol. Med. 87, 1111-1121. doi: 10.1007/s00109-009-0512-x

Borrelli, F., Fasolino, I., Romano, B., Capasso, R., Maiello, F., Coppola, D., et al. (2013). Beneficial effect of the non-psychotropic plant cannabinoid cannabigerol on experimental inflammatory bowel disease. Biochem. Pharmacol. 85, 1306-1316. doi: 10.1016/j.bcp.2013.01.017

Borrelli, F., Romano, B., Petrosino, S., Pagano, E., Capasso, R., Coppola, D., et al. (2015). Palmitoylethanolamide, a naturally occurring lipid, is an orally effective intestinal anti-inflammatory agent. Br. J. Pharmacol. 172, 142-158. doi: 10.1111/bph.12907

Brierley, S. M., and Linden, D. R. (2014). Neuroplasticity and dysfunction after gastrointestinal inflammation. Nat. Rev. Gastroenterol. Hepatol. 11, 611-627. doi: $10.1038 /$ nrgastro.2014.103

Brodie, J. S., Di Marzo, V., and Guy, G. W. (2015). Polypharmacology shakes hands with complex aetiopathology. Trends Pharmacol. Sci. 36, 802-821. doi: 10.1016/j.tips.2015.08.010

Burstein, S. (2015). Cannabidiol (CBD) and its analogs: a review of their effects on inflammation. Bioorg. Med. Chem. 23, 1377-1385. doi: 10.1016/ j.bmc.2015.01.059

Campos, A. C., Moreira, F. A., Gomes, F. V., Del Bel, E. A., and Guimarães, F. S. (2012). Multiple mechanisms involved in the largespectrum therapeutic potential of cannabidiol in psychiatric disorders. Philos. Trans. R. Soc. Lond. B Biol. Sci. 367, 3364-3378. doi: 10.1098/rstb.20 11.0389

Capasso, R., Borrelli, F., Aviello, G., Romano, B., Scalisi, C., Capasso, F., et al. (2008). Cannabidiol, extracted from Cannabis sativa, selectively inhibits inflammatory hypermotility in mice. Br. J. Pharmacol. 154, 1001-1008. doi: 10.1038/bjp.2008.177

Capasso, R., Orlando, P., Pagano, E., Aveta, T., Buono, L., Borrelli, F., et al. (2014). Palmitoylethanolamide normalizes intestinal motility in a model of post-inflammatory accelerated transit: involvement of $\mathrm{CB} 1$ receptors and TRPV1 channels. Br. J. Pharmacol. 171, 4026-4037. doi: 10.1111/bph. 12759
CBD with other minor constituents present in Cannabis sativa, also in the light of recent positive effects exerted by CBD BDS (also named GWP42003) in IBD patients (Irving et al., 2015).

\section{AUTHOR CONTRIBUTIONS}

EP performed experiments and was responsible for acquisition, analysis and interpretation of data. BR, SF, and OP performed experiments. $\mathrm{FP}$ and $\mathrm{AL}$ evaluated endocannabinoid levels. $\mathrm{RC}, \mathrm{AI}, \mathrm{VD}$, and $\mathrm{FB}$ were responsible for conception and design, analysis and interpretation of data and redaction of the manuscript.

\section{FUNDING}

This research was in part supported by GW Pharmaceuticals, Cambridge.

Corsetti, M., and Tack, J. (2015). Naloxegol, a new drug for the treatment of opioid-induced constipation. Expert Opin. Pharmacother. 16, 399-406. doi: 10.1517/14656566.2015.991306

Curtis, M. J., Bond, R. A., Spina, D., Ahluwalia, A., Alexander, S. P., Giembycz, M. A., et al. (2015). Experimental design and analysis and their reporting: new guidance for publication in BJP. Br. J. Pharmacol. 172, 3461-3471. doi: 10.1111/bph.12856

de Meijer, E. P., Bagatta, M., Carboni, A., Crucitti, P., Moliterni, V. M., Ranalli, P., et al. (2003). The inheritance of chemical phenotype in Cannabis sativa L. Genetics 163, 335-346.

De Petrocellis, L., Ligresti, A., Moriello, A. S., Allarà, M., Bisogno, T., Petrosino, S., et al. (2011). Effects of cannabinoids and cannabinoid-enriched Cannabis extracts on TRP channels and endocannabinoid metabolic enzymes. Br. J. Pharmacol. 163, 1479-1494. doi: 10.1111/j.1476-5381.2010.01166.x

De Petrocellis, L., Orlando, P., Moriello, A. S., Aviello, G., Stott, C., Izzo, A. A., et al. (2012). Di Marzo v. cannabinoid actions at TRPV channels: effects on TRPV3 and TRPV4 and their potential relevance to gastrointestinal inflammation. Acta Physiol. 204, 255-266. doi: 10.1111/j.1748-1716.2011.02338.x

DeLong, G. T., Wolf, C. E., Poklis, A., and Lichtman, A. H. (2010). Pharmacological evaluation of the natural constituent of Cannabis sativa, cannabichromene and its modulation by $\Delta(9)$-tetrahydrocannabinol. Drug Alcohol Depend. 112, 126-133. doi: 10.1016/j.drugalcdep.2010.05.019

Duncan, M., and Izzo, A. A. (2015). "Phytocannabinoids and the gastrointestinal system," in Handbook of Cannabis, ed. R. G. Pertwee (Oxford: Oxford University Press), 227-244.

Esposito, G., De Filippis, D., Cirillo, C., Iuvone, T., Capoccia, E., Scuderi, C., et al. (2013). Cannabidiol in inflammatory bowel diseases: a brief overview. Phytother. Res. 27, 633-636. doi: 10.1002/ptr.4781

Hill, A. J., Williams, C. M., Whalley, B. J., and Stephens, G. J. (2012). Phytocannabinoids as novel therapeutic agents in CNS disorders. Pharmacol. Ther. 133, 79-97. doi: 10.1016/j.pharmthera.2011.09.002

Huestis, M. A. (2005). Pharmacokinetics and metabolism of the plant cannabinoids, delta9-tetrahydrocannabinol, cannabidiol and cannabinol. Handb. Exp. Pharmacol. 168, 657-690. doi: 10.1007/3-540-26573-2_23

Irving, P. M., Iqbal, T., Nwokolo, C., Subramanian, S., Bloom, S. L., Prasad, N., et al. (2015). Sa1264 A randomised, double-blind, placebo-controlled, parallel group, multi-centred pilot study to assess the symptomatic treatment of ulcerative colitis with Cannabidiol. Gastroenterology 148, S275. doi: 10.1016/S00165085(15)30904-5

Izzo, A. A., Capasso, R., Aviello, G., Borrelli, F., Romano, B., Piscitelli, F., et al. (2012). Inhibitory effect of cannabichromene, a major non-psychotropic cannabinoid extracted from Cannabis sativa, on inflammation-induced 
hypermotility in mice. Br. J. Pharmacol. 166, 1444-1460. doi: 10.1111/j.14765381.2012.01879.x

Izzo, A. A., Muccioli, G. G., Ruggieri, M. R., and Schicho, R. (2015). Endocannabinoids and the digestive tract and bladder in health and disease. Handb. Exp. Pharmacol. 231, 423-447. doi: 10.1007/978-3-319-20825-1_15

Izzo, A. A., Pinto, L., Borrelli, F., Capasso, R., Mascolo, N., and Capasso, F. (2000). Central and peripheral cannabinoid modulation of gastrointestinal transit in physiological states or during the diarrhoea induced by croton oil. $\mathrm{Br}$. J. Pharmacol. 129, 1627-1632. doi: 10.1038/sj.bjp.0703265

Jamontt, J. M., Molleman, A., Pertwee, R. G., and Parsons, M. E. (2010). The effects of Delta-tetrahydrocannabinol and cannabidiol alone and in combination on damage, inflammation and in vitro motility disturbances in rat colitis. Br. J. Pharmacol. 160, 712-723. doi: 10.1111/j.1476-5381.2010. 00791.x

Krawisz, J. E., Sharon, P., and Stenson, W. F. (1984). Quantitative assay for acute intestinal inflammation based on myeloperoxidase activity. Assessment of inflammation in rat and hamster models. Gastroenterology 87, 1344-1350.

Kristjánsson, G., Venge, P., Wanders, A., Lööf, L., and Hällgren, R. (2004). Clinical and subclinical intestinal inflammation assessed by the mucosal patch technique: studies of mucosal neutrophil and eosinophil activation in inflammatory bowel diseases and irritable bowel syndrome. Gut 53, 1806-1812. doi: 10.1136/gut.2003.036418

Lin, X. H., Yuece, B., Li, Y. Y., Feng, Y. J., Feng, J. Y., Yu, L. Y., et al. (2011). A novel CB receptor GPR55 and its ligands are involved in regulation of gut movement in rodents. Neurogastroenterol. Motil. 23, 862-e342. doi: 10.1111/j.1365-2982.2011.01742.x

Massa, F., Marsicano, G., Hermann, H., Cannich, A., Monory, K., Cravatt, B. F., et al. (2004). The endogenous cannabinoid system protects against colonic inflammation. J. Clin. Invest. 113, 1202-1209. doi: 10.1172/JCI200419465

McPartland, J. M., Duncan, M., Di Marzo, V., and Pertwee, R. G. (2015). Are cannabidiol and $\Delta(9)$-tetrahydrocannabivarin negative modulators of the endocannabinoid system? A systematic review. Br. J. Pharmacol. 172, 737-753. doi: 10.1111/bph.12944

McPartland, J. M., and Russo, E. B. (2014). "Non-phytocannabinoid constituents of Cannabis and herbal synergy," in Handbook of Cannabis, ed. R. G. Pertwee (Oxford: Oxford University Press), 280-295.

Naftali, T., Mechulam, R., Lev, L. B., and Konikoff, F. M. (2014). Cannabis for inflammatory bowel disease. Dig. Dis. 32, 468-474. doi: 10.1159/000358155

Pertwee, R. G. (2008). The diverse CB1 and CB2 receptor pharmacology of three plant cannabinoids: delta9-tetrahydrocannabinol, cannabidiol and delta9-tetrahydrocannabivarin. Br. J. Pharmacol. 153, 199-215. doi: 10.1038/ sj.bjp.0707442

Piscitelli, F., Carta, G., Bisogno, T., Murru, E., Cordeddu, L., Berge, K., et al. (2011). Effect of dietary krill oil supplementation on the endocannabinoidome of metabolically relevant tissues from high-fat-fed mice. Nutr. Metab. (Lond) 8, 51. doi: 10.1186/1743-7075-8-51

Pol, O., and Puig, M. M. (1997). Reversal of tolerance to the antitransit effects of morphine during acute intestinal inflammation in mice. Br. J. Pharmacol. 122, 1216-1222. doi: 10.1038/sj.bjp.0701472

Pol, O., and Puig, M. M. (2004). Expression of opioid receptors during peripheral inflammation. Curr. Top. Med. Chem. 4, 51-61. doi: 10.2174/1568026 043451519

Potter, D. J. (2014). A review of the cultivation and processing of cannabis (Cannabis sativa L.) for production of prescription medicines in the UK. Drug Test. Anal. 6, 31-38. doi: 10.1002/dta.1531

Rao, S. S., Rattanakovit, K., and Patcharatrakul, T. (2016). Diagnosis and management of chronic constipation in adults. Nat. Rev. Gastroenterol. Hepatol. 13, 295-305. doi: 10.1038/nrgastro.2016.53

Ravikoff Allegretti, J., Courtwright, A., Lucci, M., Korzenik, J. R., and Levine, J. (2013). Marijuana use patterns among patients with inflammatory bowel disease. Inflamm. Bowel Dis. 19, 2809-2814. doi: 10.1097/01.MIB.0000435851. 94391.37

Reddy, B. S. (1976). Dietary factors and cancer of the large bowel. Semin. Oncol. 3, 351-359.

Romano, B., Borrelli, F., Fasolino, I., Capasso, R., Piscitelli, F., Cascio, M. G., et al. (2013). The cannabinoid TRPAl agonist cannabichromene inhibits nitric oxide production in macrophages and ameliorates murine colitis. Br. J. Pharmacol. 169, 213-229. doi: 10.1111/bph.12120

Romano, B., Borrelli, F., Pagano, E., Cascio, M. G., Pertwee, R. G., and Izzo, A. A. (2014). Inhibition of colon carcinogenesis by a standardized Cannabis sativa extract with high content of cannabidiol. Phytomedicine 21, 631-639. doi: 10.1016/j.phymed.2013.11.006

Russo, E. B. (2011). Taming THC: potential cannabis synergy and phytocannabinoid-terpenoid entourage effects. Br. J. Pharmacol. 163, 1344-1364. doi: 10.1111/j.1476-5381.2011.01238.x

Ryberg, E., Larsson, N., Sjögren, S., Hjorth, S., Hermansson, N. O., Leonova, J., et al. (2007). The orphan receptor GPR55 is a novel cannabinoid receptor. Br. J. Pharmacol. 152, 1092-1101. doi: 10.1038/sj.bjp.0707460

Schicho, R., and Storr, M. (2012). Topical and systemic cannabidiol improves trinitrobenzene sulfonic acid colitis in mice. Pharmacology 89, 149-155. doi: $10.1159 / 000336871$

Somani, S. J., Modi, K. P., Majumdar, A. S., and Sadarani, B. N. (2015). Phytochemicals and their potential usefulness in inflammatory bowel disease. Phytother. Res. 29, 339-350. doi: 10.1002/ptr.5271

Stančić, A., Jandl, K., Hasenöhrl, C., Reichmann, F., Marsche, G., Schuligoi, R., et al. (2015). The GPR55 antagonist CID16020046 protects against intestinal inflammation. Neurogastroenterol. Motil. 27, 1432-1445. doi: 10.1111/ nmo.12639

Storr, M., Devlin, S., Kaplan, G. G., Panaccione, R., and Andrews, C. N. (2014). Cannabis use provides symptom relief in patients with inflammatory bowel disease but is associated with worse disease prognosis in patients with Crohn's disease. Inflamm. Bowel Dis. 20, 472-480. doi: 10.1097/01.MIB.0000440982.79036.d6

Syed, Y. Y., McKeage, K., and Scott, L. J. (2014). Delta-9tetrahydrocannabinol/cannabidiol (Sativex ${ }^{\circledR}$ ): a review of its use in patients with moderate to severe spasticity due to multiple sclerosis. Drugs $74,563-578$. doi: 10.1007/s40265-014-0197-5

Taleban, S., Colombel, J. F., Mohler, M. J., and Fain, M. J. (2015). Inflammatory bowel disease and the elderly: a review. J. Crohns Colitis 9, 507-515. doi: 10.1093/ecco-jcc/jjv059

Vezza, T., Rodríguez-Nogales, A., Algieri, F., Utrilla, M. P., Rodriguez-Cabezas, M. E., and Galvez, J. (2016). Flavonoids in inflammatory bowel disease: a review. Nutrients 8:E211. doi: 10.3390/nu8040211

Wallace, J. L., Flannigan, K. L., McKnight, W., Wang, L., Ferraz, J. G., and Tuitt, D. (2013). Pro-resolution, protective and anti-nociceptive effects of a cannabis extract in the rat gastrointestinal tract. J. Physiol. Pharmacol. 64, 167-175.

Weiss, A., and Friedenberg, F. (2015). Patterns of cannabis use in patients with inflammatory bowel disease: a population based analysis. Drug Alcohol Depend. 156, 84-89. doi: 10.1016/j.drugalcdep.2015.08.035

Welty, T. E., Luebke, A., and Gidal, B. E. (2014). Cannabidiol: promise and pitfalls. Epilepsy Curr. 14, 250-252. doi: 10.5698/1535-7597-14.5.250

Wilkinson, J. D., Whalley, B. J., Baker, D., Pryce, G., Constanti, A., Gibbons, S., et al. (2003). Medicinal cannabis: is delta9-tetrahydrocannabinol necessary for all its effects? J. Pharm. Pharmacol. 55, 1687-1694. doi: 10.1211/0022357022304

Williamson, E. M., and Evans, F. J. (2000). Cannabinoids in clinical practice. Drugs 60, 1303-1314. doi: 10.2165/00003495-200060060-00005

Zielińska, M., Jarmuż, A., Wasilewski, A., Sałaga, M., and Fichna, J. (2015). Role of transient receptor potential channels in intestinal inflammation and visceral pain: novel targets in inflammatory bowel diseases. Inflamm. Bowel Dis. 21, 419-427. doi: 10.1097/MIB.0000000000000234

Conflict of Interest Statement: The authors declare that the research was conducted in the absence of any commercial or financial relationships that could be construed as a potential conflict of interest.

Copyright (C) 2016 Pagano, Capasso, Piscitelli, Romano, Parisi, Finizio, Lauritano, Marzo, Izzo and Borrelli. This is an open-access article distributed under the terms of the Creative Commons Attribution License (CC BY). The use, distribution or reproduction in other forums is permitted, provided the original author(s) or licensor are credited and that the original publication in this journal is cited, in accordance with accepted academic practice. No use, distribution or reproduction is permitted which does not comply with these terms. 